\title{
JOURNAL.RU
}

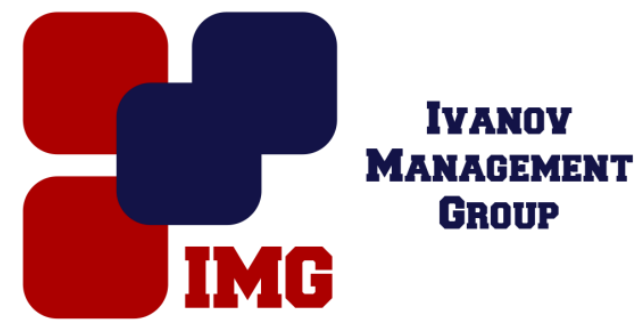

Сюй Бинцзе

Московский педагогический государственный университет

Москва, Россия

doi: $10.18411 / 1 \mathrm{j}-31-05-2017-35$

idsp 000001:1j-31-05-2017-35

\section{Пути развития лексико-фразеологического поля «литература»}

\section{Аннотация}

В Статье рассмотрено лексико-фразеологическое поле «литература» и его развитие в современное время. Подчёркивается, что данное поле открытое и в его соства входят неологизмы, в том числе однословные и несколькословные неологизмы. Лексико-фразеологическое поле «литература»пополняют элементы, называющие новые явления литературного процесса.

Ключевые слова: лексико-фразеологическое поле, единица, сема, литература, неологизм, термин.

В 21 веке изучение лексических полей в структурно-системном аспекте вышло на новый уровень, в основу которого легли наблюдения таких учёных, как Н.Н.Амосова [Амосова 1963: 7-9], А.В.Кунин[Кунин 1986:26], И.И.Чернышева[Чернышева1970:39]， .И.Антропова[Антропова1977: 8], И.А.Бангерт[Бангерт 1980:51-58], Л.С. Куркова[Куркова 1980:4-22], А.И.Пичкур[Пичкур1984], начавших с середины 70-х XX века анализировать семантику объединений фразеологических единиц и оперирующих при этом термином фразеологическое поле. Ряд исследователей (Л.А. Бутарева[Бутарева 1974:27], В.Л.Дашевская[Дашевская 1977:143-152], З.Ф Скнар[Скнар 1978], В.И. Смирнова[Смирнова 1980] и др.) рассмотрели фразеологическое поле как самостоятельную систему и определили его как «замкнутую микросистему, соотносимую экстралингвистическими и лингвистическими связями с соответствующим лексическим полем» [Ермоленко2011: 10]. 
В то же время в описании фразеологических единиц наметилось иное направление: такие учёные, как В.П. Губарев[Губарев 1983: 11-23], Л.М. Золотова[Золотова 1979:38-47], Е.М. Ножин[Ножин 1966], М.И. Семко[Семко 1974] охарактеризовали фразеосемантическое поле как часть общего лексикосемантического поля. По мнению Е.М. Ножина, «предварительно можно предположить, что семантические группы лексики и фразеологии «сосуществуют», то есть с подавляющим большинством общих понятий соотносятся определенные круги, как лексики, так и фразеологии. Вследствие этого представляется вполне реальным построение лексико - фразеологических семантических полей» [Ножин 1966]. Понятие лексико-фразеологического поля вслед за Л.И. Антроповой мы понимаем как совокупность лексических и фразеологических единиц, объединенных общей семой. Оно включает «в себя лексемы разных частей речи и фразеологические единицы различного типа. Внутри поля выделяются лексико-семантические и лексико-фразеологические микрополя, которые, в свою очередь, включают синонимические ряды и антонимические пары» [Антропова 1978].

Изучение лексико-фразеологического поля (далее ЛФП) находится на начальном этапе, и в своей статье мы рассмотрим лишь один из аспектов его анализа, а именно охарактеризуем пути пополнения новыми единицами. Материалом для наблюдений мы выбрали ЛФП «Литература», которое до настоящего времени не становилось объектом специального лингвистического рассмотрения. Это поле принадлежит к числу открытых, то есть может пополняться новыми компонентами, потому что развивается сама литература и наука о ней. В настоящее время лексико-фразеологическое поле «литература» пополнилось рядом новых терминов, которые требуют лингвистической характеристики. К их числу принадлежат: постмодернизм, постреализм, неосентиментализм, неокритический реализм, онтологический реализм, метафизический реализм и др.

Большинство из этих терминов имеют в составе поля статус неологизмов. Неологизм (от греческого языка neos- «новый», logos- «слово») - это слово или оборот речи, созданные для обозначения нового предмета или выражения нового понятия [Козырев 2004: 69-83].

Д. Э. Розенталь считает, что неологизмы - это новые слова, которые еще не стали привычными и повседневными наименованиями соответствующих предметов и понятий [Розенталь 1991: 98]. Н.М. Шанский выражает похожее мнение, указывая, что неологизмы - это новые лексические образования, 
которые возникают в силу общественной необходимости для обозначения нового предмета или явления, сохраняют ощущение новизны для носителей языка и которые еще не вошли или не входили в общелитературное употребление [Шанский 2007: 112]. Одна из основоположниц русской теоретической лексикологии и лексикографии Н.3. Котелова считает, что существует несколько лингвистических теорий, пытающихся раскрыть языковую сущность такого явления, как неологизм [Котелова 1988: 46-63]. По виду языковой единицы неологизмы делятся на неолексемы, неофраземы и неосемемы (слова и фразеологизмы). Неолексемы - это новые слова, являющиеся результатом заимствования или процессов словообразования [Горбачевич 1984]. Н.3. Котелова даёт определение неофраземы, которые понимает как «новые фразеологизмы и устойчивые сочетания слов с формирующейся идиоматичной семантикой, или аналитические сочетания» [Котелова 1990:8-9]. Неосемемы - это новые значения старых слов и фразеологизмов[Котелова 1988:46-63]. Так, у существительного демонтаж появилось переносное значение, сформировавшееся в публицистическом стиле «уничтожение или коренное преобразование чего-либо. Поэтому можно сказать, что для неологизма в лингвистике нет единого определения. Термин «неологизм» имеет разные определения, он распространяется не только на лексемы, но и на устойчивые сочетания.

Неологизмы появляются в каком-то языке различными путями: словообразовательная деривация - образование новых слов из существующих в языке морфем по известным (обычно продуктивным) моделям (например: тысячник, прозападный,фейс-контроль). Семантическая деривация - развитие в уже существующем слове нового, вторичного значения на основе сходства вновь обозначаемого явления с явлением уже известным (например: черепашка,сборник,бройлер); заимствование слов из других языков (например:месседж, смс, шейпинг) [Казимирова 2016].

В состав поля «Литература» входят однословные и несколькословные неологизмы.

Среди элементов первой группы в первую очередь следует назвать термин модернизм, который, войдя в число общепризнанных обозначений, соотносится с рядом новых понятий. Модернизм - это условное обозначение периода культуры конца XIX - середины XX в., включающее совокупность нереалистических философско-художественных направлений в искусстве этой эпохи, которые объединяет идея обновления, пересмотра философских основ, 
творческих принципов, самого языка классического искусства XIX в.[Белокурова 2005] Этот термин имеет заимствованное происхождение, причем на его роль источника претендуют два языка: французский, где слово moderne означает «современный, новейший», и итальянский, где слово modernism, образованное от латинского прилагательного modernus, т.e. «современный, недавний», приобрело значение «современное течение». В силу графического подобия второй вариант происхождения термина модернизм нам кажется более убедительным. Адаптируясь к условиям русского языка, существительное приобрело категорию мужского рода, чему способствовал фонетический облик слова, имеющий сходство с наименованиями литературных направлений, как классицизм, сентиментализм, романтизм, реализм. Мы полагаем, что, проникнув в русский язык из итальянского, термин модернизм и вытеснил альтернативное обозначение модерн. Этот термин интересен тем что в современной терминологической парадигме используется родственное ему обозначение постмодернизм.

Постмодернизм- это широкое культурное течение, в чью орбиту в последние два десятилетия 20 в. попадают философия, эстетика, искусство, наука. Термин «постмодернизм» был создан немецким ученым Р. Панвицем и использован им в статье «Кризис европейской культуры» в 1917 г. Литературовед Ф. де Онис употребил этот термин в своей книге «Антология испанской и латиноамериканской поэзии» (1934) для обозначения реакции на модернизм, однако в эстетике он не прижился. Позже термин употреблялся в работах В А. Тойнби «Постижение истории» (1947), Х. Кокса (1970-х гг.)[Лучанова 2005]. Первоначально он существовал параллельно с термином «постмодерн», также образованным помощью приставки «пост», который затем вытеснил из употребления В российское литературоведение термин постмодернизм проник во второй половине 80-х гг. путем заимствования, вероятнее всего из английского языка в значении «другая литература» и сегодня продолжает активно использоваться, утрачивая статус неологизма.

Заимствование термина постмодернизм - явление знаковое: по мнению Е.А.Земской, процессы именной префиксации «малопродуктивные в прошлом» [Земская: 139] особенно активизировались в 90-е годы ХХ в. В настоящее время слова образованные по этой модели или заимствованные с сохранением структуры из иностранных языков, «передают социально и культурологически значимую семантику» [Земская 2000: 139]. Наиболее активна среди таких морфем приставка пост- с временным значением. «Русская грамматика» 
отмечает продуктивность словообразовательного типа «существительные с префиксом пост- в специальной терминологии (например, постинфекционный); [Лопатин 1997: 309] «Толковый словарь словообразовательных единиц русского языка» трактует пост- как нерегулярную префиксальную словообразовательную единицу, выделяющуюся в именах существительных[Ефремова 1996], а не в прилагательных, как утверждает «Русская грамматика» [Русская грамматика 1980]. Учитывая то, что постмодернизм, по мнению большинства исследователей, возникнув «в русле художественной культуры, очень скоро распространяется на другие сферы: философию, политику, религию, науку» [Философия культуры 1998: 352], словоэлемент пост- при образовании термина постмодернизм приобрел, возможно, решающую семантико-функциональную и стилистическую нагрузку: «Приставка «пост-» в слове «постмодернизм» обозначает некий «анапроцесс», процесс анализа, анамнеза, аналогии и анаморфозы, который перерабатывает нечто «первозабытое» [Белинков 1995: 47-59].

С помощью этой же приставки уже на русской почве $\quad$ возник $\quad$ термин постреализм. Он был введен в научный оборот российским ученым и критиком Марком Липовецким, «чтобы обозначить художественные попытки осмысления экзистенциального поединка личности с хаосом жизни» [Дементьева 2015]. Термин «постреализм» образован префиксальным способом с помощью приставки «пост», которая добавляется к производящей основе «реализм», называющей литературное направление, требующее правдивого изображения реальной действительности.

Третье однословное наименования, принадлежащее к числу неологизмов, - это термин неосентиментализм. Это название направления современной российской литературы, о появлении которого заявляют практически все известные критики. Существительное образовано от основы сентиментали́зм (заимствованного из французского языка и образованного от sentiment-чувство), которая в роли термина приобрело значение «умонастроение и соответствующее литературное направление» [энциклопедический словарь Брокгауза и Ефрона, 1890-1907]. Произведения, написанные в рамках данного художественного направления, делают упор на читательское восприятие, то есть на чувства, возникающие при их прочтении.

Термин неосентиментализм, образован приставочным способом: приставка нео- (от греческого языка. neos - новый) имеет значение «новый», 
которая добавляется к производящей основе сентиментализм. Неологизм, возникший в результате словообразовательного процесса, называет «литературное течение, которое возвращает, актуализирует память культурных архетипов» [Куртесова2007]. В основу сентиментализма XVIII века лег идеал, провозглашенный H.M. Карамзиным в повести «Бедная Лиза». Осознание ценности простых чувств частного, «маленького», негероического человека стало необычайно актуально в сегодняшней литературе [Основные направления в современной российской литературе].

Таким образом, среди новых однословных наименований, пополнивших ЛФП «Литература», встречаются однословные обозначения, маркерами которых служат приставки нео- и пост-, а сами производные слова образуются по закрепившейся в языке модели «заимствованная основа, внутренняя форма которой раскрывает основной признак литературного направления + суффикс изм, указывающий на приверженность каким-либо культурным, политическим, экономическим идеям». Все они входят в семантическую группу «Название литературного направления».

Её же пополняют и несколькословные обозначения, например неокритический реализм. Первый из компонентов содержит заимствованный из греческого языка корень kritik- со значением «разбирать, судить». На русской почве от основы критик- возникло существительное критика (оценка, способность к оценке, проверке, одна из важнейших способностей человека, предохраняющая его от последствий заблуждений и ошибок), от которого с помощью русского суффикса - еск было образовано прилагательное критический [Виноградов 2001:128]. От него с помощью приставки нео- был образован компонент рассматриваемого терминологического сочетания «неокритический», образование которого возникло на фоне калькирования английского устойчивого сочетания newcriticism. Это течение в литературной критике середины XX века, разновидность формального метода в литературоведении.«Новая критика» в США сформировалась в 1930-е годы и стала доминирующей в 1940-50-е. Теоретические основы течения заложил Аллен Тейт и другие авторы, а своё название оно получило по книге Джона Рэнсома The New Criticism[БСЭ 1926]. Основным методом анализа текста с точки зрения «Новой критики» является «глубокое прочтение» (англ. Close reading) - всесторонне раскрытие частного и общего смысла каждой фразы, исследование символики, образной системы и глубинных мотивов, заложенных автором в произведение[Литературная энциклопедия 1987]. Компонент реализм 
используется в составе данного словосочетания без изменений. Использование этого термина уходит своими корнями в «натуральную школу» русского реализма XIX века, с его пафосом отрицания действительности и изображения всех сторон жизни без ограничения [Белокурова 2005]. Как показывают наблюдения, устойчивые выражения с компонентом реализм характеризуются высокой частотностью среди не однословных наименований ЛФП «Литература».

Так, еe пополнил термин метафизический реализм, обозначающий литературное направление, расцвет которого пришелся в российской литературе на 70-е годы XX века. Его суть заключается в том, что его сторонники утверждают: в человеческой жизни существует высокий, но потаенный смысл, который нуждается в постижении. Такая жизненная позиция противопоставляется альтернативному жизненному пути - поиску и обустройству собственного места под солнцем. Термин образован путем использования в едином контексте элементов, имевших долгую историю существования в русском языке. Термин «метафизический» от слова «метафизика» (от греческого языка metaphysic - то, что после физики) образован суффиксальным способом с помощью форманта -еск. Существительное впервые фиксируется следующим образом: «Нордстет, Слов. 1780: метафизика. - От греческого языка - после физики (так назвали философские сочинения Аристотеля, помещенные после его трактатов по физике)» [Словарь современного русского литературного языка том шестой: 909].

Проделанный анализ терминов свидетельствует о том, что терминологическое ЛФП «Литература», относящееся к числу открытых полей, находится в развитии. Его пополняют элементы, называющие новые явления литературного процесса. Большинство терминологических неологизмов обозначают художественные направления, продолжающие литературные тенденции прошлого (классицизм, реализм и др.) . Как следствие, в качестве основы для них используются наименования литературных методов и течений, семантика которых конкретизируются посредством добавления аффиксов и создания устойчивых сочетаний терминологического характера. Эти процессы могут происходить как в языке - доноре, так и в заимствующем языке. При этом заимствование происходит преимущественно путем транскрипции или транслитерации для лексем и калькирования для словосочетаний. 
1. Амосова Н.Н. Основы английской фразеологии. - Ленинград: Изд-во ленинградского университета. 1963.-321 с.

2. Антропова Л.И. Проблема семантического поля и структурирование фразеологического фрагмента "порицание" // Лексико-семантическая сочетаемость в германских языках: Межвуз. сб. науч. тр. -Челябинск, 1977. -С.8-18.

3. Бангерт И.А. Внутренняя форма и значение фразеологических единиц (на материале системного исследования фразеологизмов современного немецкого языка) // Вопросы лексикологии немецкого языка: Сб. науч. тр. / Моск. гос. пед. ин-т иностр. яз. им. М. Тореза, 1980. - Вып. 159. - С.51-58.

4. Белинков А. Иллюзии и разочарования Екклесиаста // Новое литературное обозрение. 1995, №16. - С. 47-59.

5. Белокурова С.П. Словарь литературоведческих терминов -СПб, 2005.-320с.

6. Большая советская энциклопедия(БСЭ). - Изд-во:Советская энциклопедия, 1926.-719988c.

7. Бутарева Л.А. Устойчивые комплексы типа дать + существительное" ( с предлогом и без предлога) в русском языке (сравнительно с украинским и белорусским): Автореф. дис... канд. филол. наук: 10.02.01. / Самаркандск. Гос. ун-т - Самарканд, 1974.- 27 с.

8. Виноградов В.В. Русский язык -М., 2001. - 128 с

9. Горбачевич, К.С. Русский язык. Прошлое. Настоящее. Будущее / К.С. Горбачевич. - М.: Просвещение, 1984. - 191с.

10. Губарев В.П. Фразеологическая номинация и проблема мотивированности // Номинативные единицы языка и проблемы коммуникации: Сб. науч. тр. / Моск. гос. пед. ин-т иностр. яз. им. М. Тореза, 1983. - Вып. 208. - С. 11-23.

11. Гугунава Д.В. Морфемный статус препозитивной части пост- на материале постмоде [Электронный ресурс] // Литературная критика. - 2002. - Режим доступа: http://www.proza.ru/2002/12/18-116

12. Гудков Л.Д. Массовая литература как проблема. Для кого? // Новое литературное обозрение, 1996, № 22.- С.78-101.

13. Дашевская, В.Л. К вопросу о статусе фразеосемантического поля Текст./ В.Л. Дашевская// Лингвистика и методика в высшей школе. -М.: МГПИИЯ им. М. Тореза, 1977. Вып. $7 .-$ C.143-152.

14. Дементьева С.А. Жанры художественной литературы.[Электронный ресурс] // Патриотическое воспитание школьников. - 2015.- Режим доступа:http://dpadilet.kz/zhanry-xudozhestvennoj-literatury/

15. Ермоленко Е.В. Лексико-семантическое поле соматизмов в английском и русском языках ( сопоставительный анализ). Курск, 2011. - С.5.

16. Ефремова Т.Ф. Толковый словарь словообразовательных единиц русского языка / Т.Ф. Ефремова. - М.: Русский язык, 1996. - 638 с.

17. Земская Е.А. Активные процессы современного словопроизводства // Русский язык конца ХХ столетия. - М., 2000.-С.200.

18. Золотова Л.М. К проблеме регулярности в сфере фразеологической номинации // Фразеологическая система немецкого и английского языков.- Челябинск: Изд-во ЧГПИ, 1979. -С. 38-47.

19. Казимирова А.А Неологизмы в Интернет-комментариях. - М.,2016 - 206с.

20. Книгин И. А. Словарь литературоведческих терминов - Саратов, 2006.-272c.

21. Котелова, Н.3. Первый опыт лексикографического описания русских неологизмов / Н.3. Котелова // Новые слова и словари новых слов. - Л.: Наука ЛО, 1990. - С.8-9. 
22. Котелова, Н.3. Теоретические аспекты лексикографического описания неологизмов / Н.3. Котелова // Советская лексикография.-М.: Энциклопедия, 1988.- С. 46-63.

23. Козырев, В.А. Русская лексикография / В.А. Козырев, В.Д. Черняк. - М.: 2004. - С. 69-83.

24. Крысина Л. П. Толковый словарь иностранных слов.- М: Русский язык, 1998.-847с.

25. Кунин А.В. Курс фразеологии современного английского языка. - М.: Высшая школа, 1986.-336 c.

26. Куркова Л.С. Фразеологический фрагмент семантического поля «мышление» в современном немецком языке в сопоставлении с русским языком: Автореф. дис. ... канд. филол. наук. - М., 1980. -25 с.

27. Куртесова О.П. Современная русская литература (литература конца 20 века - начала 21века)[Электронный ресурс] // Учебно-методическое пособие (литература). -Троицко Печорск, 2007.- Режим доступа:/literatura/library/2014/01/07/aktivnaya-lektsiyasovremennaya-russkaya-literatura-literatura

28. Лопатин В.В. Аффиксоид // Русский язык. Энциклопедия. - М., 1997.-683c.

29. Лучанова М.Ф. История мировой литературы: Учеб. пособие. - Омск: ОмГТУ, 2005. $128 \mathrm{c}$.

30. Ножин Е.М. Вопросы использования фразеологизмов в пропаганде: Автореф. дис, .канд.филол.наук. -М., 1966. -21с.

31. Ожегов, С.И. Толковый словарь русского языка: Около 100000 слов, терминов и фразеологических выражений / С.И. Ожегов; Под ред. Л.И. Скворцов. -М.: ОНИКС-ЛИТ, Мир и Образование, 2011.-736с.

32. Основные направления в современной российской литературе. [Электронный ресурс]// Современая русская литература (краткий обзор).-2014. - Режим доступа:la/literatura/library/2014/11/19/osnovnye-napravleniya-v-sovremennoy-rossiyskoyliterature

33. Пичкур А.И: Основные лексико-фразеологические поля в публицистических текстах современного немецкого языка Текст.: дис. . канд. филол. наук: 10.02.04./А.И. Пичкур. M., 1984.-26 c.

34. Померанц Г. С. Новая философская энциклопедия: В 4 т. -М.: Мысль. Под редакцией В. С. Стёпина. 2001.

35. Розенталь, Д.Э. Современный русский язык / Д.Э. Розенталь, И.Б. Голуб, М.А. Теленкова. - М.: Высшая школа, 1991. - 560с.

36. Русская грамматика. - М.-Л., 1980. - Т.1.

37. Семко М.И. Семасиологическое исследование лексико- фразеологического поля, связанного с понятием deception (на материале английских публицистических текстов): Автореф. дис. ... канд. филол. наук. - М., 1974. - 22 с.

38. Скнар 3.Ф. Глагольные соматические фразеологизмы современ- ного английского языка (в сопоставлении с однотипными единицами укр. яз.): Дис. ... канд. филол. наук. - Нежин, 1978. $-336 \mathrm{c}$.

39. Словарь современного русского литературного языка. - М., Л.: Издательство Академии Наук СССР , 1957. -С. 909.

40. Смирнова В.И. Фразеологические единицы, образованные членами лексикосемантической группы с общим значением атмосферных явлений природы: Автореф. дис. ... канд. филол. наук. - М., 1980. - 25 с.

41. Чернышева И.И., 1970 б: Чернышева И.И. Некоторые семантические категории фразеологизмов в сопоставлении с категориями лексики. В кн.: Труды Сам.ун-та, новая серия, Самарканд, 1970, вып.178, с.239-242.

42. Шанский, Н.М. Лексикология современного русского языка - М.: ЛКИ, 2007. - 304c.

43. Энциклопедический словарь Брокгауза и Ефрона (1890-1907).-СПБ.: Семеновская Типолитография, 1890-1907.-86 т. 